\title{
Functional improvement and correlations with symptomatic improvement in adults with attention deficit hyperactivity disorder receiving long-acting methylphenidate
}

\author{
J. K. Buitelaar ${ }^{1 *}$, M. Casas ${ }^{2}$, A. Philipsen ${ }^{3}$, J. J. S. Kooij ${ }^{4}$, J. A. Ramos-Quiroga ${ }^{2}$, J. Dejonckheere ${ }^{5}$, \\ J. C. van Oene ${ }^{6}$ and B. Schäuble ${ }^{7}$ \\ ${ }^{1}$ Department of Cognitive Neuroscience, University Medical Centre, St Radboud and Karakter Child and Adolescent Psychiatry University \\ Centre, Nijmegen, The Netherlands \\ ${ }^{2}$ Department of Psychiatry, Hospital Universitari Vall d'Hebron and Department of Psychiatry and Legal Medicine, Universitat Autònoma \\ de Barcelona, Spain \\ ${ }^{3}$ Department of Psychiatry, University Hospital Medical Centre, Freiburg, Germany \\ ${ }^{4}$ PsyQ, Psycho-Medical Programmes, Programme Adult ADHD, Den Haag, The Netherlands \\ ${ }^{5}$ SGS Life Sciences, Mechelen, Belgium \\ ${ }^{6}$ Janssen-Cilag EMEA, Tilburg, The Netherlands \\ ${ }^{7}$ Janssen-Cilag EMEA, Neuss, Germany
}

Background. Data on the relationship between core symptoms and daily functioning in adults with attention deficit hyperactivity disorder (ADHD) are limited. Daily functioning was assessed as part of an open-label extension, and associations with symptom scores were evaluated.

Method. After a 5-week double-blind study with adults with ADHD receiving osmotic-controlled release oral delivery system (OROS) methylphenidate (MPH) 18, 36 or $72 \mathrm{mg} /$ day, or placebo, participants were eligible for a 7-week open-label extension in which all patients received OROS MPH. Data for the Conners' Adult ADHD Rating Scale - Observer: Screening Version (CAARS-O:SV) (primary endpoint) have been presented previously. Secondary endpoints included the observer self-reported short version of the CAARS (CAARS-S:S) and the Clinical Global Impressions - Severity Scale (CGI-S). Daily functioning and quality of life were assessed using the Sheehan Disability Scale (SDS) and the Quality of Life Enjoyment and Satisfaction Questionnaire (Q-LES-Q) respectively. In post-hoc analyses, changes in CAARS-O:SV were evaluated in subgroups. Relationships between symptom and functional outcomes were evaluated in a multivariate regression analysis.

Results. A total of 370 patients entered the open-label extension. Significant improvements from baseline in CAARSO:SV were similar regardless of sex, ADHD subtype, prior treatment or psychiatric co-morbidity. Significant improvements from double-blind baseline were also seen for the CAARS-S:S, CGI-S, SDS and Q-LES-Q. Improvements in the CAARS-O:SV Hyperactivity/Impulsivity subscale were associated with improvements in SDS total and subscale scores, and in the Q-LES-Q score at open-label endpoint. Improvements in CAARS-O:SV Inattention subscale and CGI-S scores were not significantly associated with functional changes.

Conclusions. Improvements in ADHD symptoms relating to hyperactivity and impulsivity in adults receiving OROS $\mathrm{MPH}$ are associated with improvements in daily functioning and quality of life.

Received 4 November 2010; Revised 18 April 2011; Accepted 3 May 2011; First published online 1 June 2011

Key words: ADHD, adult, daily functioning, methylphenidate, prolonged release, stimulant.

\section{Introduction}

In addition to core symptoms of hyperactivity, inattention and impulsivity, adults with attention deficit

\footnotetext{
* Address for correspondence: Professor J. K. Buitelaar, Department of Cognitive Neuroscience (204), PO Box 9101, 6500 HB Nijmegen, The Netherlands.

(Email : j.buitelaar@psy.umcn.nl)
}

hyperactivity disorder (ADHD) experience deficits in executive function, including inhibition of motor impulses, verbal fluency, working memory, planning, organization and cognitive flexibility (Barkley, 1998; Woods et al. 2002; Hervey et al. 2004; Roth \& Saykin, 2004; Boonstra et al. 2005b; Lijffijt et al. 2005). These, together with the core symptoms, affect daily functioning, leading to impairments in education, work, relationships and social activities (Kessler et al. 2006;

The online version of this article is published within an Open Access environment subject to the conditions of the Creative Commons Attribution-NonCommercial-ShareAlike licence <http://creativecommons.org/licenses/by-nc-sa/2.5/ $>$. The written permission of Cambridge University Press must be obtained for commercial re-use. 
Barkley et al. 2008). It is, however, unclear to what extent the symptoms contribute to impairments in daily life.

Stimulant medications such as methylphenidate (MPH) are highly effective for treatment of the core ADHD symptoms (Faraone et al. 2004; Medori et al. 2008; Peterson et al. 2008; Adler et al. 2009; Buitelaar et al. 2009a). There is also evidence that MPH treatment can improve symptoms relating to executive functioning in parallel with improvements in core symptoms (Aron et al. 2003; Boonstra et al. 2005a; Fallu et al. 2006). Few studies, however, have investigated the relationship between symptomatic improvement and improvements in daily functioning in patients with ADHD. A meta-analysis of clinical trials of atomoxetine in children and adolescents with ADHD found that symptomatic improvements (ADHD Rating Scale-IV-Parent Version: Investigator-administered; ADHDRS-IV-Parent:Inv) showed moderate to strong correlations with improvements in daily functioning, measured on the Life Participation Scale (LPS) (Buitelaar et al. 2009b).

The osmotic-controlled release oral delivery system (OROS) MPH formulation is designed to deliver $\mathrm{MPH}$ in a controlled manner providing extended control of symptoms during the day. Studies have shown that once-daily treatment with OROS MPH is effective and well tolerated for treatment of ADHD in children and adolescents (Pelham et al. 2001; Wolraich et al. 2001; Swanson et al. 2003), and adults (Biederman et al. 2006; Medori et al. 2008; Adler et al. 2009; Buitelaar et al. 2009a). In a 5-week, randomized, double-blind, placebo-controlled trial [Long Acting MethylpheniDate in Adult ADHD (LAMDA)], all three doses of OROS MPH tested led to significant improvements in symptoms of ADHD in adults, assessed using the investigator-rated 18-item Conners' Adult ADHD Rating Scale-Observer: Screening Version (CAARS-O:SV) (Medori et al. 2008). OROS $\mathrm{MPH}$ was also associated with statistically significant functional and global improvements, as measured using the non-disease-specific Sheehan Disability Scale (SDS) and the Clinical Global Impressions Severity Scale (CGI-S). Regression analyses of data from LAMDA showed correlations between scores on the CAARS Hyperactivity/Impulsivity subscale and both SDS and quality-of-life scores (Rösler et al. 2011).

In a 7-week open-label extension to LAMDA, subjects who received placebo in the double-blind phase showed significant improvement in CAARS-O:SV total score after 1 week of treatment in the extension, with further improvements at weeks 3 and 7, and CAARS-O:SV total scores continued to improve in patients who had previously received OROS MPH, with significant changes from baseline at weeks 3 and
7 (Buitelaar et al. 2009a). Here, we present data on functional and other secondary endpoints from the LAMDA open-label extension, and also explore the relationship between symptomatic and functional outcomes during the cumulative (double-blind and openlabel) 12 weeks of treatment in adults with ADHD.

\section{Method}

\section{Study design and patients}

Adults with ADHD $(n=401)$ were randomized to receive OROS MPH $(18,36$ or $72 \mathrm{mg} /$ day $)$ or placebo for 5 weeks. Those who completed the double-blind phase or discontinued study medication as a result of poor tolerability after $\geqslant 7$ days of treatment were eligible to participate in a 7-week open-label extension during which they received flexibly dosed OROS MPH in the range $18-90 \mathrm{mg} /$ day. To maintain blinding from the double-blind phase, all patients started the openlabel phase at a dose of $36 \mathrm{mg} /$ day $(18 \mathrm{mg} /$ day in Germany), which could subsequently be adjusted to optimize efficacy and tolerability according to the clinical judgement of the investigator.

Patients eligible for the initial placebo-controlled trial were adults (aged 18-65 years) with ADHD according to the criteria of DSM-IV and confirmed by the Conners' Adult ADHD Diagnostic Interview for DSMIV (CAADID). The designs of the initial study and the open-label extension, together with full inclusion and exclusion criteria, have been published previously (Medori et al. 2008; Buitelaar et al. 2009a).

The study was conducted according to Good Clinical Practice and the 'Recommendations Guiding Physicians in Biomedical Research Involving Human Subjects' contained in the Declaration of Helsinki. The study protocol was approved by the ethics committee at each site. All patients provided written, informed consent before participating in the study.

\section{Endpoints and analyses}

The primary efficacy assessment in the double-blind and open-label phases was the 18-item CAARS-O:SV total score (Medori et al. 2008; Buitelaar et al. 2009a). ADHD symptoms were also assessed using the patient self-report short version of the CAARS (CAARS-S:S). During the open-label phase, assessments were made at weeks 1 and 7 (CAARS-O:SV was also evaluated at week 3) with a post-study visit 1 week after the last dose of OROS MPH (whether this occurred in the open-label or in the double-blind phase). Global condition was evaluated using the CGI-S, for which the investigator rates the patient's severity of illness on a seven-point scale ranging from 1 (not ill) to 7 (extremely severe). Change in global condition was 
evaluated at endpoint using the CGI Change (CGI-C), a seven-point scale ranging from 1 (very much improved) to 7 (very much worse) (NIMH, 1985). Daily functioning was assessed using the SDS, a generic instrument with three 10-point visual analogue scales designed to measure the extent to which (i) work, (ii) social life and leisure activities and (iii) home life and family responsibilities are impaired (Sheehan et al. 1996). Quality of life was measured using the Quality of Life Enjoyment and Satisfaction Questionnaire (Q-LES-Q) Short Form, a 16-item self-administered questionnaire designed to assess the degree of enjoyment and satisfaction experienced by patients in various areas of daily functioning. Patients rated items concerning physical health, feelings, work, household duties, work and leisure-time activities and social relationships across five response categories, ranging from very poor to very good (Endicott et al. 1993). The Q-LES-Q has been validated in adults with ADHD (Mick et al. 2008).

Subjects who were treated in the double-blind phase could continue into the open-label phase. Efficacy analyses were performed on the open-label intent-to-treat (ITT) population, defined as those subjects who received at least one dose of open-label study medication and had at least one post-baseline assessment during the open-label phase.

Changes in CAARS-O:SV, CAARS-S:S and Q-LES-Q were analysed using a paired-samples $t$ test. A regression analysis was performed for each functional scale on the change from double-blind baseline at the end of the open-label period, including baseline score, age, country, double-blind OROS MPH dose (or placebo), sex, change in CAARS-O:SV Hyperactivity/ Impulsivity subscale score, change in CAARS-O:SV Inattention subscale score, and change in CGI-S at end of double-blind. The CAARS-O:SV total score was found to correlate strongly with the two CAARS-O:SV subscale scores, and was therefore not included in the analysis.

\section{Results}

\section{Patient disposition}

In the double-blind phase, 401 patients received at least one dose of study medication and 365 patients (91\%) completed the 5-week double-blind study period. Full details of patient disposition in the double-blind phase have been published previously (Medori et al. 2008).

Of the 377 eligible patients, 370 entered the 7-week open-label extension. The ITT population comprised 369 patients, of whom 93 had received placebo and 276 had received OROS MPH in the double-blind phase. The mean ( \pm S.D.) daily dose of OROS MPH in the open-label phase was $46.5 \pm 14.2 \mathrm{mg}$ (range $18-82 \mathrm{mg}$ ) and the mean maximum dose was $57.6 \pm 18.1 \mathrm{mg}$ (range 18-108 mg). The overall mean daily dose in the open-label phase was similar regardless of the original treatment group $(45.6-48.0 \mathrm{mg})$. The most frequent maximum doses of OROS MPH in the open-label phase were $54 \mathrm{mg}(36 \%), 36 \mathrm{mg}(26 \%)$ and $72 \mathrm{mg}$ $(25 \%)$. The most frequent final doses in the open-label extension were $54 \mathrm{mg}$ (34\%), $36 \mathrm{mg}$ (29\%) and $72 \mathrm{mg}$ $(20 \%)$.

In total, 337 patients completed the open-label extension. Of the 33 patients $(8.9 \%)$ who withdrew from the study prematurely, 18 withdrew because of an adverse event, five were lost to follow-up, one withdrew consent, one withdrew because of lack of efficacy, and eight withdrew for other reasons. Baseline characteristics of the patients who entered the openlabel phase are shown in Table 1.

\section{Efficacy assessments}

CAARS-O:SV scores at baseline, double-blind endpoint and open-label endpoint are shown in Table 2. Patients who switched from placebo to OROS MPH at the start of the open-label phase experienced improvement in total CAARS-O:SV score from doubleblind endpoint after 1 week of treatment with OROS $\mathrm{MPH}$ [mean ( \pm S.D.) change at week $1=-3.5 \pm 8.5$, $p<0.001 v$. double-blind endpoint], whereas those who had previously received OROS MPH showed significant improvement relative to double-blind endpoint from week 3 of the open-label phase onwards (mean change at week $3=-4.3 \pm 8.2, p<0.001$ ). At open-label endpoint, the mean changes from doubleblind endpoint in the CAARS-O:SV score were $-8.4 \pm 9.4$ and $-6.1 \pm 9.3$ in the prior placebo and prior OROS MPH groups respectively (both $p<0.001$ $v$. double-blind endpoint; $p=0.0073$ for betweengroup comparison). Similarly, significant changes in CAARS-O:SV Hyperactivity/Impulsivity and Inattention subscale scores were seen from double-blind endpoint to open-label endpoint in both the prior placebo and prior OROS MPH arms $(p<0.001 v$. double-blind endpoint for both subscales) (Table 2). In the post-hoc subgroup analysis, changes in CAARSO:SV score from double-blind endpoint to open-label endpoint were of similar magnitude regardless of patient subgroup (Table 3 ).

At week 7 of the open-label extension, significant improvement from double-blind endpoint was observed in the prior placebo and prior MPH groups for the CAARS-S:S, CGI-S and Q-LES-Q scales (Table 2). Significant improvement in SDS score was also seen (Table 2), and the results were similar for each of the three SDS subscales (Fig. 1). Clinically significant 
Table 1. Baseline demographics of all patients who entered the open-label phase

\begin{tabular}{|c|c|c|c|}
\hline & $\begin{array}{l}\text { Prior placebo } \\
(n=93)\end{array}$ & $\begin{array}{l}\text { Prior OROS MPH } \\
(n=277)\end{array}$ & $\begin{array}{l}\text { All subjects } \\
(n=370)\end{array}$ \\
\hline Age (years), mean \pm s.D. & $34.8 \pm 9.6$ & $34.2 \pm 10.5$ & $34.3 \pm 10.3$ \\
\hline \multicolumn{4}{|l|}{ Sex, $n(\%)$} \\
\hline Male & $58(62.4)$ & $141(50.9)$ & $199(53.8)$ \\
\hline Female & $35(37.6)$ & $136(49.1)$ & $171(46.2)$ \\
\hline \multicolumn{4}{|l|}{ Race, $n(\%)$} \\
\hline White & $91(97.8)$ & $272(98.2)$ & $343(98.1)$ \\
\hline Other & $2(2.2)$ & $5(1.8)$ & $7(1.9)$ \\
\hline Weight $(\mathrm{kg})$, mean \pm s.D. & $79.8 \pm 18.2$ & $77.4 \pm 16.7$ & $78.0 \pm 17.1$ \\
\hline Body mass index $\left(\mathrm{kg} / \mathrm{m}^{2}\right)$, mean \pm s.D. & $25.8 \pm 5.4$ & $25.8 \pm 4.8$ & $25.8 \pm 5.0$ \\
\hline Age at ADHD diagnosis (years), mean \pm s.D. & $31.7 \pm 12.6$ & $29.7 \pm 14.1$ & $30.2 \pm 13.8$ \\
\hline \multicolumn{4}{|l|}{ ADHD subtype, $n(\%)$} \\
\hline Combined & $65(69.9)$ & $194(70.0)$ & $259(70.0)$ \\
\hline Predominantly inattentive & $23(24.7)$ & $68(24.5)$ & $91(24.6)$ \\
\hline Predominantly hyperactive-impulsive & $2(2.2)$ & $14(5.1)$ & $16(4.3)$ \\
\hline Not otherwise specified & $3(3.2)$ & $1(0.4)$ & $4(1.1)$ \\
\hline \multicolumn{4}{|l|}{ Prior mood and anxiety disorders, $n(\%)$} \\
\hline Currently active & $10(10.8)$ & $35(12.6)$ & $45(12.2)$ \\
\hline Not currently active & $23(24.7)$ & $88(31.8)$ & $111(30.0)$ \\
\hline \multicolumn{4}{|l|}{ Prior substance use disorder, $n(\%)$} \\
\hline Currently active & 0 & $1(0.4)$ & $1(0.3)$ \\
\hline Not currently active & $12(12.9)$ & $35(12.6)$ & $47(12.7)$ \\
\hline
\end{tabular}

ADHD, Attention deficit hyperactivity disorder; OROS, osmotic-controlled release oral delivery system ; $\mathrm{MPH}$, methylphenidate; S.D., standard deviation.

disability in terms of SDS subscale scores (score $\geqslant 5$ ) was present in most patients (80-89\%) at double-blind baseline. At open-label endpoint, the percentage of patients with clinically significant disability was substantially reduced for each of the three SDS subscales (39-43\%). At open-label endpoint, median (range) CGI-C scores were $2.0(1-4)$ and $2.0(1-5)$ in the prior placebo and prior OROS MPH groups respectively.

\section{Post-study visit}

One week after the last dose of OROS MPH (poststudy visit), CAARS-O:SV scores worsened significantly compared with open-label endpoint in both the prior placebo [mean $( \pm$ S.D. $)$ increase $=6.8 \pm 8.3$ ] and prior OROS MPH $(7.8 \pm 9.3)$ groups (both $p<0.001)$. CGI-S scores had also worsened significantly from open-label endpoint at the post-study visit, with a median change of 0.0 and 1.0 in the prior placebo and prior OROS MPH groups respectively (both $p<0.001$ v. open-label endpoint).

\section{Regression analysis}

Regression analysis performed on the change in the functional scales from baseline to open-label endpoint showed that improvement in the CAARS-O:SV Hyperactivity/Impulsivity subscale at the end of the double-blind period was associated with functional improvement at the end of the open-label period for the SDS total and subscale scores, and the Q-LES-Q score (Table 4). Neither change in the CAARS-O:SV Inattention subscale nor change in CGI-S at the end of the double-blind period was significantly associated with functional outcome at the end of the open-label period. Overall, the total explained variances of the change in functional scale from baseline to open-label endpoint varied from $30 \%$ to $39 \%$ (Table 2).

\section{Discussion}

In this 7-week open-label extension following a 5-week double-blind, placebo-controlled trial, patients who received OROS MPH 18-90 mg/day experienced improvements in symptoms of ADHD, functioning and quality of life regardless of whether they were initially randomized to OROS $\mathrm{MPH}$ or placebo. These benefits were found to be similar when patients were categorized according to sex, ADHD subtype, prior treatment or the presence of psychiatric comorbidities. Although the absolute benefits of OROS 
Table 2. Rating scale scores at baseline (week 0), double-blind endpoint (week 5) and open-label endpoint (week 12)

\begin{tabular}{|c|c|c|}
\hline Scale & $\begin{array}{l}\text { Prior placebo } \\
(n=93)\end{array}$ & $\begin{array}{l}\text { Prior OROS } \\
\text { MPH }(n=276)\end{array}$ \\
\hline \multicolumn{3}{|l|}{ CAARS-O:SV total score } \\
\hline Baseline & $37.2 \pm 7.2$ & $36.5 \pm 6.9$ \\
\hline Double-blind endpoint & $29.5 \pm 10.6$ & $24.3 \pm 10.9$ \\
\hline Change $v$. baseline & $-7.7 \pm 9.9^{*}$ & $-12.3 \pm 10.6^{*}$ \\
\hline Open-label endpoint & $21.1 \pm 10.0$ & $18.2 \pm 9.1$ \\
\hline Change $v$. double-blind endpoint & $-8.4 \pm 9.4^{*}$ & $-6.1 \pm 9.3^{*}$ \\
\hline Change $v$. baseline & $-16.0 \pm 10.8^{*}$ & $-18.3 \pm 10.8^{*}$ \\
\hline \multicolumn{3}{|l|}{ CAARS-O:SV Hyperactivity/Impulsivity } \\
\hline Baseline & $17.1 \pm 5.5$ & $16.9 \pm 5.1$ \\
\hline Double-blind endpoint & $13.1 \pm 6.4$ & $11.5 \pm 5.9$ \\
\hline Change $v$. baseline & $-4.0 \pm 5.5^{*}$ & $-5.3 \pm 5.7^{*}$ \\
\hline Open-label endpoint & $9.3 \pm 5.4$ & $8.6 \pm 4.8$ \\
\hline Change $v$. double-blind endpoint & $-3.8 \pm 5.0^{*}$ & $-3.0 \pm 4.8^{*}$ \\
\hline Change $v$. baseline & $-7.8 \pm 6.0^{*}$ & $-8.3 \pm 6.1^{*}$ \\
\hline \multicolumn{3}{|l|}{ CAARS-O:SV Inattention } \\
\hline Baseline & $20.0 \pm 4.3$ & $19.7 \pm 4.1$ \\
\hline Double-blind endpoint & $16.4 \pm 6.0$ & $12.8 \pm 6.2$ \\
\hline Change $v$. baseline & $-3.6 \pm 5.2^{*}$ & $-6.9 \pm 6.1^{*}$ \\
\hline Open-label endpoint & $11.8 \pm 6.0$ & $9.6 \pm 5.3$ \\
\hline Change $v$. double-blind endpoint & $-3.8 \pm 5.0^{*}$ & $-3.0 \pm 4.8$ \\
\hline Change $v$. baseline & $-8.1 \pm 6.1^{*}$ & $-10.0 \pm 5.9^{*}$ \\
\hline \multicolumn{3}{|l|}{ CAARS-S:S } \\
\hline Baseline & $51.2 \pm 10.3$ & $50.0 \pm 11.7$ \\
\hline Double-blind endpoint & $45.8 \pm 14.1$ & $38.0 \pm 15.8$ \\
\hline Open-label endpoint & $35.2 \pm 14.6$ & $31.1 \pm 14.1$ \\
\hline Change $v$. double-blind endpoint & $-11.9 \pm 12.9^{*}$ & $-7.2 \pm 11.9^{*}$ \\
\hline \multicolumn{3}{|l|}{ CGI-S } \\
\hline Baseline & $5.0(3-7)$ & $5.0(1-7)$ \\
\hline Double-blind endpoint & $5.0(2-6)$ & $4.0(1-7)$ \\
\hline Open-label endpoint & $3.0(1-6)$ & $3.0(1-6)$ \\
\hline Change $v$. double-blind endpoint & $-1.0(-4 \text { to } 1)^{*}$ & $-1.0(-4 \text { to } 2)^{*}$ \\
\hline \multicolumn{3}{|l|}{ SDS } \\
\hline Baseline & $19.8 \pm 5.1$ & $19.6 \pm 5.2$ \\
\hline Double-blind endpoint & $17.6 \pm 5.2$ & $14.5 \pm 7.0$ \\
\hline Open-label endpoint & $12.6 \pm 6.3$ & $11.8 \pm 6.4$ \\
\hline Change $v$. double-blind endpoint & $-4.6 \pm 5.8^{*}$ & $-2.8 \pm 6.0^{*}$ \\
\hline \multicolumn{3}{|l|}{ Q-LES-Q } \\
\hline Baseline & $48.8 \pm 14.1$ & $49.4 \pm 15.2$ \\
\hline Double-blind endpoint & $53.4 \pm 15.2$ & $55.9 \pm 16.4$ \\
\hline Open-label endpoint & $58.2 \pm 16.4$ & $60.3 \pm 16.2$ \\
\hline Change $v$. double-blind endpoint & $5.6 \pm 16.1^{*}$ & $4.7 \pm 14.8$ \\
\hline
\end{tabular}

CAARS-O:SV, Conners' Adult ADHD Rating Scale - Observer: Screening Version; CAARS-S:S, CAARS - Self: Short Version; CGI-S, Clinical Global Impressions Severity Scale; SDS, Sheehan Disability Scale; Q-LES-Q, Quality of Life Enjoyment and Satisfaction Questionnaire; OROS, osmotic-controlled release oral delivery system; MPH, methylphenidate.

Scores are mean \pm standard deviation or median (range).

${ }^{*} p \leqslant 0.003 v$. double-blind baseline. 
Table 3. Change from double-blind endpoint to open-label endpoint in CAARS total scores in patient subgroups

\begin{tabular}{|c|c|c|}
\hline Subgroup & $\begin{array}{l}\text { Prior } \\
\text { placebo }\end{array}$ & $\begin{array}{l}\text { Prior OROS } \\
\text { MPH }\end{array}$ \\
\hline \multicolumn{3}{|l|}{ Sex } \\
\hline \multicolumn{3}{|l|}{ Male } \\
\hline$n$ & 58 & 141 \\
\hline $\begin{array}{l}\text { Mean } \pm \text { S.D. } \\
p \text { value }\end{array}$ & $\begin{array}{c}-7.6 \pm 8.6 \\
<0.001\end{array}$ & $\begin{array}{c}-5.6 \pm 8.8 \\
<0.001\end{array}$ \\
\hline \multicolumn{3}{|l|}{ Female } \\
\hline$n$ & 35 & 135 \\
\hline $\begin{array}{l}\text { Mean } \pm \text { S.D. } \\
p \text { value }\end{array}$ & $\begin{array}{c}-9.7 \pm 10.7 \\
<0.001\end{array}$ & $\begin{array}{c}-6.6 \pm 9.8 \\
<0.001\end{array}$ \\
\hline \multicolumn{3}{|c|}{ ADHD subtype } \\
\hline \multicolumn{3}{|c|}{ Combined } \\
\hline$n$ & 6 & 193 \\
\hline Mean \pm S.D. & $-9.2 \pm 10.3$ & $-6.6 \pm 9.9$ \\
\hline$p$ value & $<0.001$ & $<0.001$ \\
\hline \multicolumn{3}{|c|}{ Predominantly inattentive } \\
\hline$n$ & 23 & 68 \\
\hline $\begin{array}{l}\text { Mean } \pm \text { S.D. } \\
p \text { value }\end{array}$ & $\begin{array}{c}-6.3 \pm 7.1 \\
<0.001\end{array}$ & $\begin{array}{c}-5.1 \pm 8.0 \\
<0.001\end{array}$ \\
\hline \multicolumn{3}{|c|}{ Prior treatment } \\
\hline \multicolumn{3}{|c|}{ Treatment-naïve } \\
\hline$n$ & 83 & 254 \\
\hline $\begin{array}{l}\text { Mean } \pm \text { S.D. } \\
p \text { value }\end{array}$ & $\begin{array}{c}-8.1 \pm 9.4 \\
<0.001\end{array}$ & $\begin{array}{c}-6.0 \pm 9.3 \\
<0.001\end{array}$ \\
\hline \multicolumn{3}{|l|}{ Non-naïve } \\
\hline$n$ & 10 & 22 \\
\hline $\begin{array}{l}\text { Mean } \pm \text { S.D. } \\
p \text { value }\end{array}$ & $\begin{array}{c}-10.6 \pm 9.7 \\
0.007\end{array}$ & $\begin{array}{c}-7.4 \pm 8.9 \\
<0.001\end{array}$ \\
\hline \multicolumn{3}{|c|}{ Psychiatric co-morbidity } \\
\hline \multicolumn{3}{|c|}{ No co-morbidity } \\
\hline$n$ & 78 & 230 \\
\hline $\begin{array}{l}\text { Mean } \pm \text { S.D. } \\
p \text { value }\end{array}$ & $\begin{array}{c}-8.6 \pm 9.3 \\
<0.001\end{array}$ & $\begin{array}{c}-6.1 \pm 9.0 \\
<0.001\end{array}$ \\
\hline \multicolumn{3}{|c|}{ Co-morbidity present } \\
\hline$n$ & 15 & 46 \\
\hline $\begin{array}{l}\text { Mean } \pm \text { S.D. } \\
p \text { value }\end{array}$ & $\begin{array}{c}-7.3 \pm 10.3 \\
0.016\end{array}$ & $\begin{array}{c}-5.9 \pm 10.6 \\
<0.001\end{array}$ \\
\hline \multicolumn{3}{|c|}{ Mood-anxiety disorder } \\
\hline$n$ & 10 & 33 \\
\hline $\begin{array}{l}\text { Mean } \pm \text { S.D. } \\
p \text { value }\end{array}$ & $\begin{array}{c}-7.7 \pm 10.2 \\
0.040\end{array}$ & $\begin{array}{c}-4.7 \pm 10.9 \\
0.018\end{array}$ \\
\hline
\end{tabular}

ADHD, Adult attention deficit hyperactivity disorder; CAARS, Conners' Adult ADHD Rating Scale; OROS, osmotic-controlled release oral delivery system; MPH, methylphenidate; S.D., standard deviation.

$\mathrm{MPH}$ in the open-label phase were generally greater in patients who were previously untreated, those who received placebo for 5 weeks in the double-blind phase had not 'caught up' in terms of CAARS-O:SV score at week 12 with those who had received 12 weeks of
OROS MPH. This may be related to the flexible-dose design of the open-label phase, and may also be a result of patients who had the potential for further improvement receiving fixed, and therefore potentially suboptimal, doses in the double-blind phase. At a post-study visit 1 week after discontinuation, there was no evidence of rebound.

The post-hoc regression analysis showed that improvement in the CAARS-O:SV Hyperactivity/ Impulsivity subscale was more closely associated with functional improvement (SDS) and improvement in quality of life (Q-LES-Q) than improvement in the CAARS-O:SV Inattention subscale. It is possible that this lack of correlation between observer-reported inattention and subject-reported functional disability reflects deficits in subjects' self-observation. After 12 weeks of treatment, no significant associations between change in CAARS-O:SV Inattention score or CGI-S at double-blind endpoint (week 5) and change in SDS or Q-LES-Q were observed, although the change in CAARS-O:SV Hyperactivity/Impulsivity subscale was significantly associated with functional improvement for all SDS subscales and Q-LES-Q. These results are consistent with a similar analysis carried out at week 5 (double-blind endpoint), when the change from double-blind baseline in the CAARSO:SV Hyperactivity/Impulsivity subscale was significantly associated with both SDS total score and Q-LES$\mathrm{Q}$ score (both $p<0.001$ ) (Rösler et al., in press).

In a meta-analysis of four studies of atomoxetine in children and adolescents with ADHD, a moderate to strong correlation $(r=-0.68)$ was observed between changes in the LPS daily functioning scale and the ADHDRS-IV-Parent:Inv total, although no $p$ value was provided for this correlation (Buitelaar et al. $2009 b$ ). Of the LPS subscales, the Self-control subscale showed higher correlations than the Happy/Social subscale with the symptom measures. Regression analysis showed high sensitivity for functional measures to changes in symptom severity. Of note, impairments in daily functioning in children seemed to be driven by symptoms of inattention, suggesting that the effect of ADHD symptoms on daily living may change as individuals move from childhood to adulthood.

The magnitude of improvement in SDS score in the present study compares favourably with that demonstrated in a 4-year open-label study of atomoxetine, in which the change in SDS total score was -3.8 (Adler et al. 2008b). Indeed, the improvement in SDS in the present study was almost as large as that seen in a 12-week open-label study of duloxetine in patients with major depressive disorder, in which the mean SDS total score was reduced from 18.7 to 9.5 (Hudson et al. 2007). Although the SDS has not been validated 
Table 4. Regression coefficients of symptomatic improvement and other independent variables on functional improvement. The analysis was performed for each functional scale on the change from baseline to open-label endpoint including baseline score, age, country, treatment group, sex, and change in CAARS Hyperactivity/Impulsivity, CAARS Inattention and CGI-S at double-blind endpoint

Functional improvement at open-label endpoint

\begin{tabular}{|c|c|c|c|c|c|}
\hline & \\
\hline & SDS: Work & SDS: Social Life & SDS: Family Life & SDS: Total Score & Q-LES-Q \\
\hline \multicolumn{6}{|l|}{$\begin{array}{l}\text { Symptomatic improvement } \\
\text { at double-blind endpoint }\end{array}$} \\
\hline CAARS Inattention & $0.0355(0.3125)$ & $0.0217(0.4850)$ & $-0.0061(0.8546)$ & $0.0720(0.4289)$ & $-0.3768(0.1008)$ \\
\hline $\begin{array}{l}\text { CAARS Hyperactivity/ } \\
\text { Impulsivity }\end{array}$ & $0.0945(0.0039)$ & $0.0750(0.0111)$ & $0.1181(0.0002)$ & $0.2517(0.0031)$ & $-0.4650(0.0282)$ \\
\hline CGI-S & $0.1792(0.3590)$ & $0.2465(0.1498)$ & $0.1582(0.3905)$ & $0.5312(0.2929)$ & $-0.4476(0.7228)$ \\
\hline \multicolumn{6}{|l|}{ Variable } \\
\hline Age & $0.0119(0.3774)$ & $0.0308(0.1949)$ & $0.0111(0.3793)$ & $0.1136(0.1061)$ & $0.0677(0.4303)$ \\
\hline Country ${ }^{\mathrm{a}}$ & N.A. $(0.6405)$ & N.A. $(0.1766)$ & N.A. $(0.4743)$ & N.A. $(0.4411)$ & N.A. $(0.4841)$ \\
\hline $\begin{array}{l}\text { Treatment: OROS } \\
\text { MPH } 18 \mathrm{mg}\end{array}$ & $0.0831(0.8252)$ & $-0.2090(0.8592)$ & $0.1283(0.7154)$ & $-1.1474(0.7452)$ & $-1.9413(0.4196)$ \\
\hline $\begin{array}{l}\text { Treatment: OROS } \\
\text { MPH } 36 \mathrm{mg}\end{array}$ & $0.0848(0.8239)$ & $0.9664(0.3991)$ & $-0.1849(0.6010)$ & $3.8278(0.2638)$ & $-0.7736(0.7478)$ \\
\hline $\begin{array}{l}\text { Treatment: OROS } \\
\text { MPH } 72 \mathrm{mg}\end{array}$ & $0.4294(0.2805)$ & $2.6460(0.0242)$ & $0.1031(0.7779)$ & $8.4345(0.0157)$ & $-1.5635(0.5425)$ \\
\hline Age $\times$ OROS MPH $18 \mathrm{mg}$ & - & - & - & $0.0528(0.5853)$ & - \\
\hline Age $\times$ OROS MPH 36 mg & - & - & - & $-0.1159(0.2212)$ & - \\
\hline Age $\times$ OROS MPH $72 \mathrm{mg}$ & - & - & - & $-0.2232(0.0185)$ & - \\
\hline Sex: Female & $0.2727(0.3103)$ & $0.3852(0.1043)$ & $0.3754(0.1428)$ & $1.1392(0.1113)$ & $0.6127(0.7221)$ \\
\hline Variance $\left(R^{2}\right)$ & 0.3289 & 0.3971 & 0.3710 & 0.3514 & 0.3092 \\
\hline
\end{tabular}

CAARS, Conners' Adult ADHD Rating Scale; CGI-S, Clinical Global Impressions - Severity Scale; SDS, Sheehan Disability Scale; Q-LES-Q, Quality of Life Enjoyment and Satisfaction Questionnaire; OROS, osmotic-controlled release oral delivery system; MPH, methylphenidate; N.A., not available.

Values given are point estimates with $p$ values (for difference from zero) in parentheses.

a Point estimates were calculated separately for each participating country.

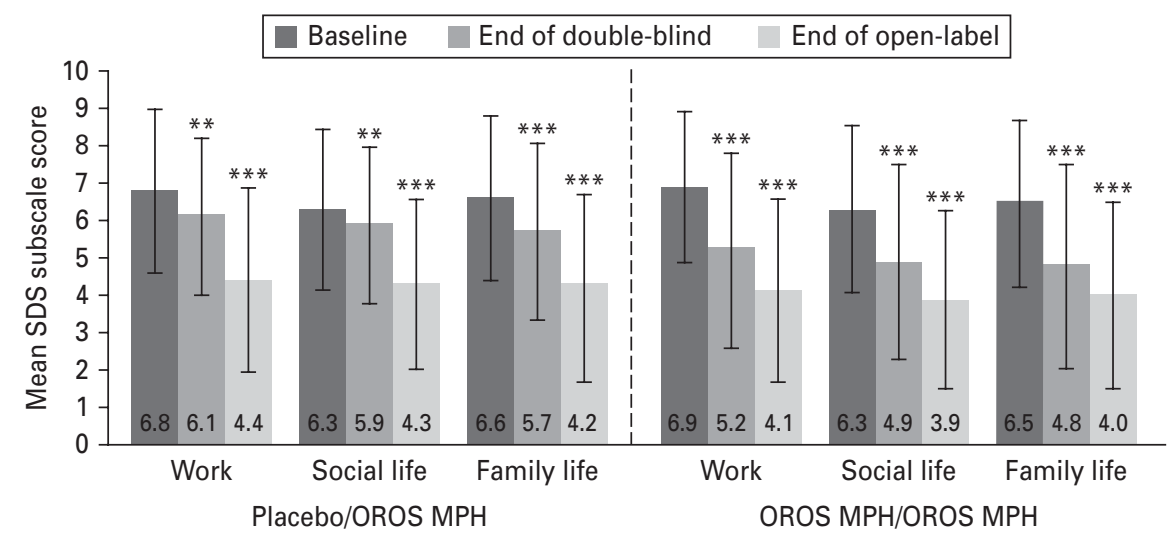

Fig. 1. Mean ( \pm standard deviation) Sheehan Disability Scale (SDS) subscale scores at baseline, double-blind endpoint and open-label endpoint for patients previously treated with placebo (left panel, $n=93$ ) or osmotic-controlled release oral delivery system (OROS) methylphenidate (MPH) (right panel, $n=269$ ). ${ }^{* *} p<0.01, * * *<0.001$ versus baseline.

formally in adults with ADHD, it has been validated in patients with bipolar disorder (Arbuckle et al. 2009), social anxiety disorder (Hambrick et al. 2004) and panic disorder (Leon et al. 1992), and has been shown to be sensitive to treatment effects in patients with anxiety disorders, depression or premenstrual dysphoric disorder (Sheehan \& Sheehan, 2008).

In the present study, significant improvement from baseline in quality of life, as measured by the Q-LES-Q, was observed. These are consistent with the 
quality of life improvements reported in other studies in adults with ADHD receiving stimulant medication. In two 7-week studies in adults with ADHD treated with mixed amphetamine salts, improvements in health-related quality of life assessed using the disease-specific ADHD Impact Module (AIM-A) were significantly greater than those in subjects receiving placebo (Spencer et al. 2008a,b). Further analysis of data from these two studies showed that the improvements in quality of life, particularly the Performance and Function subscale of the AIM-A, were correlated with improvements in executive function (Brown \& Landgraf, 2010). Similarly, 8-week, 14-week and 6-month studies of adults with ADHD receiving atomoxetine have shown significant improvements versus placebo using the Adult ADHD Quality of Life Scale (AAQoL; Matza et al. 2007; Adler et al. 2008a, 2009) or the 36-item Short Form questionnaire (SF-36; Adler et al. 2006). In the latter study, the SF-36 score was shown to be significantly correlated with CAARSO:SV.

Dosing in the open-label phase was flexible, based on clinical judgement, which more closely reflects clinical practice than fixed dosing. The patient cohort was, however, enrolled according to stringent inclusion and exclusion criteria, which may limit the generalizability of the data. In addition, it should be noted that the regression analysis was carried out on a post-hoc basis and the results remain to be confirmed in a prospective study.

In conclusion, the results of this analysis of data from a randomized, double-blind study and its openlabel extension show that improvements in ADHD symptoms relating to hyperactivity and impulsivity in adults receiving OROS MPH are correlated with improvements in daily functioning and quality of life.

\section{Acknowledgements}

This study was supported by Janssen-Cilag EMEA (Europe, Middle East and Africa). Editorial support with the drafting and completion of the manuscript was provided by D. Booth (Bioscript Stirling Ltd, UK) and funded by Janssen-Cilag EMEA.

\section{Declaration of Interest}

J. K. Buitelaar has, in the past 3 years, been a consultant, a member of an advisory board and/or a speaker for Janssen-Cilag BV, Eli Lilly, Bristol-Myer Squibb, Organon/Shering Plough, UCB, Shire, Medice, and Servier. He is not an employee or a shareholder of any of these companies, and has no other financial or material support, including expert testimony, patents or royalties. M. Casas has, in the past 3 years, been a consultant, a member of an advisory board and/or a speaker for Janssen-Cilag, Eli Lilly, Shire and Rubió. He has received research grants from Janssen-Cilag, Rubió and Eli Lilly. He is not an employee or a shareholder of any of these companies, and has no other financial or material support, including expert testimony, patents or royalties. A. Philipsen has, in the past 3 years, been a consultant, a member of an advisory board and/or a speaker for Janssen-Cilag, Eli Lilly, Shire, Novartis. She has received research funding from Medice and Janssen-Cilag. She is not an employee or a shareholder of any of these companies, and has no other financial or material support, including expert testimony, patents or royalties. J. J. S. Kooij has been a speaker for Janssen-Cilag BV and Eli Lilly and has received research grants from JanssenCilag BV and Shire. She is not an employee or a shareholder of any of these companies, and has no other financial or material support, including expert testimony, patents or royalties. J. A. Ramos-Quiroga has, in the past 3 years, been a consultant, a member of an advisory board and/or a speaker for Janssen-Cilag, Eli Lilly, Shire and Rubió. He has received research grants from Janssen-Cilag, Rubió, Eli Lilly and Alicia Koplowitz Foundation. He is not an employee or a shareholder of any of these companies, and has no other financial or material support, including expert testimony, patents or royalties. J. Dejonckheere is a consultant working on behalf of SGS-Life Science Services, a company employed by Janssen-Cilag EMEA to provide statistical analysis. J. C. van Oene is a former employee of Janssen-Cilag EMEA. B. Schäuble is an employee of Janssen-Cilag EMEA.

\section{References}

Adler LA, Spencer TJ, Levine LR, Ramsey JL, Tamura R, Kelsey D, Ball SG, Allen AJ, Biederman J (2008a). Functional outcomes in the treatment of adults with ADHD. Journal of Attention Disorders 11, 720-727.

Adler LA, Spencer TJ, Williams DW, Moore RJ, Michelson D (2008b). Long-term, open-label safety and efficacy of atomoxetine in adults with ADHD: final report of a 4-year study. Journal of Attention Disorders 12, 248-253.

Adler LA, Sutton VK, Moore RJ, Dietrich AP, Reimherr FW, Sangal RB, Saylor KE, Secnik K, Kelsey DK, Allen AJ (2006). Quality of life assessment in adult patients with attention-deficit/hyperactivity disorder treated with atomoxetine. Journal of Clinical Psychopharmacology 26, 648-652.

Adler LA, Zimmerman B, Starr HL, Silber S, Palumbo J, Orman C, Spencer T (2009). Efficacy and safety of OROS methylphenidate in adults with attention-deficit/ hyperactivity disorder: a randomized, placebo-controlled, 
double-blind, parallel group, dose-escalation study. Journal of Clinical Psychopharmacology 29, 239-247.

Arbuckle R, Frye MA, Brecher M, Paulsson B, Rajagopalan K, Palmer S, Degl'Innocenti A (2009). The psychometric validation of the Sheehan Disability Scale (SDS) in patients with bipolar disorder. Psychiatry Research 165, 163-174.

Aron AR, Dowson JH, Sahakian BJ, Robbins TW (2003). Methylphenidate improves response inhibition in adults with attention-deficit/hyperactivity disorder. Biological Psychiatry 54, 1465-1468.

Barkley RA (1998). Attention-deficit hyperactivity disorder. Scientific American 279, 66-71.

Barkley RA, Murphy KR, Fischer M (2008). ADHD in Adults: What the Science Says. Guilford Press: New York.

Biederman J, Mick E, Surman C, Doyle R, Hammerness P, Harpold T, Dunkel S, Dougherty M, Aleardi M, Spencer T (2006). A randomized, placebo-controlled trial of OROS methylphenidate in adults with attention-deficit/hyperactivity disorder. Biological Psychiatry 59, 829-835.

Boonstra AM, Kooij JJ, Oosterlaan J, Sergeant JA, Buitelaar JK (2005a). Does methylphenidate improve inhibition and other cognitive abilities in adults with childhood-onset ADHD? Journal of Clinical and Experimental Neuropsychology 27, 278-298.

Boonstra AM, Oosterlaan J, Sergeant JA, Buitelaar JK (2005b). Executive functioning in adult ADHD: a meta-analytic review. Psychological Medicine 35, 1097-1108.

Brown TE, Landgraf JM (2010). Improvements in executive function correlate with enhanced performance and functioning and health-related quality of life: evidence from 2 large, double-blind, randomized, placebocontrolled trials in ADHD. Postgraduate Medicine 122, 42-51.

Buitelaar JK, Ramos-Quiroga JA, Casas M, Kooij JJ, Niemela A, Konofal E, Dejonckheere J, Challis BH Medori R (2009a). Safety and tolerability of flexible dosages of prolonged-release OROS methylphenidate in adults with attention-deficit/hyperactivity disorder. Neuropsychiatric Disease and Treatment 5, 457-466.

Buitelaar JK, Wilens TE, Zhang S, Ning Y, Feldman PD (2009b). Comparison of symptomatic versus functional changes in children and adolescents with ADHD during randomized, double-blind treatment with psychostimulants, atomoxetine, or placebo. Journal of Child Psychology and Psychiatry 50, 335-342.

Endicott J, Nee J, Harrison W, Blumenthal R (1993). Quality of Life Enjoyment and Satisfaction Questionnaire: a new measure. Psychopharmacology Bulletin 29, 321-326.

Fallu A, Richard C, Prinzo R, Binder C (2006). Does OROS-methylphenidate improve core symptoms and deficits in executive function? Results of an open-label trial in adults with attention deficit hyperactivity disorder. Current Medical Research and Opinion 22, 2557-2566.

Faraone SV, Spencer T, Aleardi M, Pagano C, Biederman J (2004). Meta-analysis of the efficacy of methylphenidate for treating adult attention-deficit/hyperactivity disorder. Journal of Clinical Psychopharmacology 24, 24-29.
Hambrick JP, Turk CL, Heimberg RG, Schneier FR, Liebowitz MR (2004). Psychometric properties of disability measures among patients with social anxiety disorder. Journal of Anxiety Disorders 18, 825-839.

Hervey AS, Epstein JN, Curry JF (2004). Neuropsychology of adults with attention-deficit/hyperactivity disorder: a meta-analytic review. Neuropsychology 18, 485-503.

Hudson JI, Perahia DG, Gilaberte I, Wang F, Watkin JG, Detke MJ (2007). Duloxetine in the treatment of major depressive disorder: an open-label study. BMC Psychiatry 7, 43 .

Kessler RC, Adler L, Barkley R, Biederman J, Conners CK, Demler O, Faraone SV, Greenhill LL, Howes MJ, Secnik K, Spencer T, Ustun TB, Walters EE, Zaslavky AM (2006). The prevalence and correlates of adult ADHD in the United States: results from the National Comorbidity Survey Replication. American Journal of Psychiatry 163, 716-723.

Leon AC, Shear MK, Portera L, Klerman GL (1992). Assessing impairment in patients with panic disorder: the Sheehan Disability Scale. Social Psychiatry and Psychiatric Epidemiology 27, 78-82.

Lijffijt M, Kenemans JL, Verbaten MN, van Engeland $\mathbf{H}$ (2005). A meta-analytic review of stopping performance in attention-deficit/hyperactivity disorder: deficient inhibitory motor control? Journal of Abnormal Psychology 114, 216-222.

Matza LS, Johnston JA, Faries DE, Malley KG, Brod M (2007). Responsiveness of the Adult Attention-Deficit/ Hyperactivity Disorder Quality of Life Scale (AAQoL). Quality of Life Research 16, 1511-1520.

Medori R, Ramos-Quiroga JA, Casas M, Kooij JJS, Niemelä A, Trott G-E, Lee E, Buitelaar JK (2008). A randomized, placebo-controlled trial of three fixed dosages of prolonged-release OROS methylphenidate in adults with attention-deficit/hyperactivity disorder. Biological Psychiatry 63, 981-989.

Mick E, Faraone SV, Spencer T, Zhang HF, Biederman J (2008). Assessing the validity of the Quality of Life Enjoyment and Satisfaction Questionnaire Short Form in adults with ADHD. Journal of Attention Disorders 11, 504-509.

NIMH (1985). CGI: Clinical Global Impression Scale. Psychopharmacology Bulletin 21, 839-843.

Pelham WE, Gnagy EM, Burrows-Maclean L, Williams A, Fabiano GA, Morrisey SM, Chronis AM, Forehand GL, Nguyen CA, Hoffman MT, Lock TM, Fielbelkorn K, Coles EK, Panahon CJ, Steiner RL, Meichenbaum DL, Onyango AN, Morse GD (2001). Once-a-day Concerta methylphenidate versus three-times-daily methylphenidate in laboratory and natural settings. Pediatrics 107, E105.

Peterson K, McDonagh MS, Fu R (2008). Comparative benefits and harms of competing medications for adults with attention-deficit hyperactivity disorder: a systematic review and indirect comparison meta-analysis. Psychopharmacology (Berlin) 197, 1-11.

Rösler M, Ginsberg Y, Arngrim T, Adamou M, Niemelä A, Dejonkheere J, van Oene J, Schäuble B (2011). Correlation 
of symptomatic improvements with functional improvements and patient-reported outcomes in adults with attention-deficit/hyperactivity disorder treated with OROS methylphenidate. World Journal of Biological Psychiatry. Published online: 26 April 2011. doi:10.3109/ 15622975.2011.571283.

Roth RM, Saykin AJ (2004). Executive dysfunction in attention-deficit/hyperactivity disorder: cognitive and neuroimaging findings. Psychiatric Clinics of North America 27, 83-96, ix.

Sheehan DV, Harnett-Sheehan K, Raj BA (1996). The measurement of disability. International Clinical Psychopharmacology 11 (Suppl. 3), 89-95.

Sheehan KH, Sheehan DV (2008). Assessing treatment effects in clinical trials with the discan metric of the Sheehan Disability Scale. International Clinical Psychopharmacology 23, 70-83.

Spencer TJ, Adler LA, Weisler RH, Youcha SH (2008a). Triple-bead mixed amphetamine salts (SPD465), a novel, enhanced extended-release amphetamine formulation for the treatment of adults with ADHD: a randomized, double-blind, multicenter, placebo-controlled study. Journal of Clinical Psychiatry 69, 1437-1448.
Spencer TJ, Landgraf JM, Adler LA, Weisler RH, Anderson CS, Youcha SH (2008b). Attention-deficit/ hyperactivity disorder-specific quality of life with triple-bead mixed amphetamine salts (SPD465) in adults: results of a randomized, double-blind, placebo-controlled study. Journal of Clinical Psychiatry 69, 1766-1775.

Swanson J, Gupta S, Lam A, Shoulson I, Lerner M, Modi N, Lindemulder E, Wigal S (2003). Development of a new once-a-day formulation of methylphenidate for the treatment of attention-deficit/hyperactivity disorder: proof-of-concept and proof-of-product studies. Archives of General Psychiatry 60, 204-211.

Wolraich ML, Greenhill LL, Pelham W, Swanson J, Wilens T, Palumbo D, Atkins M, McBurnett $K$, Bukstein O, August G (2001). Randomized, controlled trial of OROS methylphenidate once a day in children with attention-deficit/hyperactivity disorder. Pediatrics 108, 883-892.

Woods SP, Lovejoy DW, Ball JD (2002). Neuropsychological characteristics of adults with ADHD: a comprehensive review of initial studies. Clinical Neuropsychology 16, $12-34$. 